\title{
Perbandingan Mortalitas Pasien Anak dengan Acute Respiratory Distress Syndrome yang Menggunakan Delta Pressure Tinggi dan Rendah
}

Tressa Bayu B, Sri Martuti, Pudjiastuti

Bagian Ilmu Kesehatan Anak Fakultas Kedokteran Universitas Sebelas Maret/RSUD Dr. Moewardi, Surakarta

Latar belakang. Strategi ventilasi protektif paru (protective lung strategy) direkomendasikan dalam penanganan pasien acute respiratory distress syndrome (ARDS). Strategi tersebut mencakup pembatasan PEEP dan delta pressure pada penggunaan ventilator untuk mencegah mortalitas. Pembatasan delta pressure $\leq 13 \mathrm{mmHg}$ diharapkan dapat menurunkan angka mortalitas pasien ARDS dengan ventilator. Tujuan. Mengetahui perbandingan mortalitas pasien anak dengan ARDS yang menggunakan delta pressure tinggi dan rendah. Metode. Penelusuran rekam medis pasien anak berusia 1 bulan-18 tahun yang menderita ARDS yang dirawat di PICU dengan menggunakan ventilator.

Hasil. Studi cross sectional dari bulan September 2016 sampai dengan Maret 2017 terhadap 32 pasien anak berumur 1 bulan-18 tahun yang menderita ARDS, didapatkan hasil bahwa mortalitas pasien anak dengan ARDS lebih tinggi pada penggunaan setting ventilator dengan delta pressure tinggi $\left(\Delta \mathrm{P}>13 \mathrm{cmH}_{2} \mathrm{O}\right)$ dibandingkan dengan yang menggunakan pengaturan ventilator dengan delta pressure yang rendah $\left(\Delta \mathrm{P} \leq 13 \mathrm{cmH}_{2} \mathrm{O}\right)(\mathrm{p}<0,001$, OR 45,00 (IK95\%: 5, 47-370,02).

Kesimpulan. Pasien anak dengan ARDS yang menggunakan setting ventilator dengan delta pressure rendah, mortalitasnya lebih rendah dibandingkan dengan yang menggunakan pengaturan ventilator dengan delta pressure tinggi. Sari Pediatri 2017;19(3):156-60

Kata kunci: ARDS, pengaturan ventilator, delta pressure, mortalitas, anak

\section{Children's Mortality with Acute Respiratory Distress Syndrome between High and Low Delta Pressure}

Tressa Bayu B, Sri Martuti, Pudjiastuti

Background. Protective lung strategy recommended to manage patient with acute respiratory syndrome (ARDS). The strategy consists of limiting PEEP dan delta pressure in ventilator setting for prevent mortality. Limiting delta pressure $\leq 13 \mathrm{mmHg}$ expected for decrease the mortality of patient with ARDS.

Objective. Comparing the mortality of child with ARDS between high and low delta pressure.

Methods. Searching the medical record for child aged 1 month to 18 years that suffering from ARDS and use ventilator support in PICU.

Results. Cross sectional study was performed, data's collected from September 2016 to March 2017. The subject was 32 children aged 1 month to 18 years that suffering from ARDS. Subject mortality higher in group that used high delta pressure in the ventilator setting $\left(\Delta \mathrm{P}>13 \mathrm{cmH}_{2} \mathrm{O}\right)$ compare with the group that used low delta pressure $\left(\Delta \mathrm{P} \leq 13 \mathrm{cmH}_{2} \mathrm{O}\right)(\mathrm{p}<0.001, \mathrm{OR} 45.00$ (CI $95 \% 5.47-370.02)$.

Conclussion. Patients with ARDS that used low delta pressure in ventilator setting have lower mortality comparing with patients who used high delta pressure. Sari Pediatri 2017;19(3):156-60

Keywords: ARDS, ventilator setting, delta pressure, mortality, child

Alamat korespondensi: Dr. Tressa Bayu Bramantyo. Departemen Ilmu Kesehatan Anak Fakultas Kedokteran UNS/RSUD Dr. Moewardi, Anggrek 4. Email:dr_bayu@ymail.com 
Tressa Bayu B dkk: Perbandingan mortalitas pasien ARDS yang menggunakan delta pressure tinggi dan rendah

A

cute respiratory distress syndrome (ARDS) adalah salah satu penyakit paru akut yang memerlukan perawatan di Pediatric Intensive Care Unit (PICU) dan mempunyai angka kematian yang tinggi. ${ }^{1}$ Pendekatan dalam penggunaan model ventilasi mekanis pada pasien ARDS masih kontroversial. American European Concencus Conference Committee (AECC) merekomendasikan pembatasan volume tidal dan positive end expiratory pressure (PEEP) sebagai strategi penanganan ARDS. ${ }^{2}$

Saat ini strategi ventilasi protektif paru (protective lung strategy) direkomendasikan dalam penanganan pasien acute respiratory distress syndrome (ARDS). ${ }^{3}$ Strategi tersebut mencakup beberapa komponen penting, yaitu menurunkan volume tidal dan membatasi tekanan puncak inspirasi sama atau dibawah $30 \mathrm{cmH}_{2} \mathrm{O} .{ }^{3-5}$ Kombinasi strategi tersebut terbukti menurunkan risiko kematian pada pasien-pasien yang menggunakan ventilator. Pembatasan volume tidal (VT) berdasarkan berat badan juga digunakan untuk menurunkan risiko kematian. Volume tidal rendah yang digunakan pada kelompok survival yang lebih tinggi menggunakan rentang antara $4-8 \mathrm{ml} / \mathrm{KgBB} .{ }^{6}$

Pada tahun 2015, Brioni $\mathrm{dkk}^{8}$ melakukan penelitian yang menunjukkan bahwa faktor pembatasan delta pressure adalah faktor yang paling berpengaruh terhadap mortalitas di antara faktor yang lain, yaitu pembatasan volume tidal dan menaikkan PEEP. Selanjutnya, Guerin $\mathrm{dkk}^{7}$ melakukan penelitian lanjutan dan menemukan bahwa delta pressure $\leq 13$ $\mathrm{cmH}_{2} \mathrm{O}$ akan menurunkan risiko mortalitas pasien ARDS dibandingkan dengan delta pressure di atas 13.

Di Indonesia belum terdapat penelitian yang meneliti mengenai besarnya delta pressure sebagai prediktor mortalitas pada pasien anak dengan ventilator. Penelitian ini bertujuan untuk membuktikan bahwa delta pressure ( $\triangle \mathrm{Prs}$ ) pada pasien anak dengan ARDS yang selamat/survival berbeda dengan kelompok pasien yang meninggal.

\section{Metode}

Penelitian potong lintang (cross sectional) retrospektif analitik berlangsung di unit perawatan intensif pediatrik PICU RSUD Dr. Moewardi. Data diambil dari rekam medis pasien yang dirawat selama bulan September 2016 sampai dengan April 2017. Subjek penelitian adalah anak usia $>1$ bulan sampai dengan $\leq 18$ tahun dengan diagnosis ARDS, yaitu berdasarkan definisi dari American-European Consensus Conference, 1994. Definisi ARDS menurut konsensus tersebut adalah hipoksemia akut (tekanan oksigen arteri dibandingkan dengan fraksi oksigen inspirasi $\left[\mathrm{PaO}_{2} / \mathrm{FIO}_{2}\right] \leq 200 \mathrm{~mm}$ $\mathrm{Hg}$ ) dengan infiltrat bilateral pada rontgen thorak, dan tidak didapatkannya tanda-tanda hipertensi pulmonal. Penelitian ini telah mendapatkan persetujuan dari Komite Etik Penelitian Bakordik RSUD Dr.MoewardiFK UNS No. 518/VI/HREC/2017.

Data yang dikumpulkan dari rekam medis, antara lain, identitas pasien (meliputi nama, nomor rekam medis, usia, jenis kelamin), lama penggunaan ventilator invasif, nilai maksimal $\mathrm{PEEP}, \mathrm{FiO}_{2}$, dan $\triangle \mathrm{Prs}$ selama perawatan, lama perawatan, dan mortalitas pasien. Subyek dibagi menjadi dua kelompok menurut penggunaan delta pressure, yaitu pasien yang menggunakan delta pressure $\leq 13 \mathrm{cmH}_{2} \mathrm{O}$ (kelompok dengan delta pressure rendah) dan pasien yang menggunakan delta pressure $>13 \mathrm{cmH}_{2} \mathrm{O}$ (kelompok dengan delta pressure tinggi). Mortalitas pasien juga dikelompokkan menjadi dua, yaitu pasien yang selamat/survival dan pasien yang mengalami mortalitas. Analisis statistik dilakukan dengan program SPSS versi 17 menggunakan chi-square, nilai dianggap bermakna secara statistik bila $<0,05$.

\section{Hasil}

Selama rentang waktu penelitian dari bulan September 2016 sampai dengan April 2017, terdapat 32 anak yang masuk perawatan PICU RSUD Dr. Moewardi dengan diagnosis ARDS yang dirawat dengan ventilator invasif. Sebagian besar subjek berjenis kelamin laki-laki, rasio laki-laki dibandingkan dengan perempuan 1,13:1. Rentang usia subyek penelitian 1 bulan sampai $\leq 18$ tahun dengan sebaran terbanyak pada kelompok usia 2-5 tahun (46\%). Sembilan belas subjek (60\%) menggunakan PEEP $>5 \mathrm{cmH}_{2} \mathrm{O}$. Hanya $28 \%$ subyek memerlukan fraksi oksigen $>50 \%$. Tujuh belas subyek (53\%) dirawat selama $>10$ hari dan $70 \%$ di antaranya selamat. Dua puluh subyek (62\%) menggunakan delta pressure $\leq 13 \mathrm{cmH}_{2} \mathrm{O}$, sedangkan sisanya menggunakan delta pressure $>13 \mathrm{cmH}_{2} \mathrm{O}$. Mortalitas pada subyek penelitian yang menggunakan delta pressure $>13$ $\mathrm{cmH}_{2} \mathrm{O}$ adalah sebesar $84 \%$. Karakteristik subjek penelitian tertera pada Tabel. 1.

Dari hasil analisis statistik chi-square antara variabel 
Tressa Bayu B dkk: Perbandingan mortalitas pasien ARDS yang menggunakan delta pressure tinggi dan rendah

Tabel 1. Karakteristik subyek pasien anak dengan ARDS yang dirawat dengan ventilator invasif $(\mathrm{n}=32)$

\begin{tabular}{|c|c|c|c|}
\hline Karakteristik & Frekuensi $\mathrm{n}$ & Hidup & Meninggal \\
\hline \multicolumn{4}{|l|}{ Jenis kelamin } \\
\hline Laki-laki & 17 & 11 & 6 \\
\hline Perempuan & 15 & 9 & 6 \\
\hline \multicolumn{4}{|c|}{ Kelompok umur (tahun) } \\
\hline 1 bulan-1 & 14 & 8 & 6 \\
\hline $2-5$ & 15 & 10 & 5 \\
\hline $6-12$ & 2 & 1 & 1 \\
\hline $13-\leq 18$ & 1 & 1 & 0 \\
\hline \multicolumn{4}{|c|}{$\mathrm{PEEP}\left(\mathrm{cmH}_{2} \mathrm{O}\right)$} \\
\hline$\leq 5$ & 13 & 12 & 1 \\
\hline$>5$ & 19 & 8 & 11 \\
\hline \multicolumn{4}{|c|}{ Delta pressure $(\Delta \mathrm{Prs}),\left(\mathrm{cmH}_{2} \mathrm{O}\right)$} \\
\hline$\leq 13$ & 20 & 18 & 2 \\
\hline$>13$ & 12 & 2 & 10 \\
\hline \multicolumn{4}{|c|}{ Fraksi oksigen (\%) } \\
\hline$\leq 50$ & 23 & 15 & 8 \\
\hline$>50$ & 9 & 5 & 4 \\
\hline \multicolumn{4}{|c|}{ Length of stay (LOS), (hari) } \\
\hline $0-5$ & 4 & 1 & 3 \\
\hline $6-10$ & 11 & 7 & 4 \\
\hline$>10$ & 17 & 12 & 5 \\
\hline
\end{tabular}

dependen mortalitas dengan penggunaan delta pressure didapatkan perbedaan nilai antara kelompok yang meninggal dengan kelompok hidup/selamat, dengan nilai $\mathrm{p}<0,001$, OR 45,00 (IK95\% 5,47-370,02).

\section{Pembahasan}

Definisi ARDS pertama kali dikemukakan oleh Asbaugh pada tahun 1967. Menurut Asbaugh dkk, ${ }^{9}$ ARDS didefinisikan sebagai hipoksemia berat yang onsetnya akut, infiltrat bilateral yang difus pada foto toraks dan penurunan komplians atau daya regang paru. ${ }^{10}$

Prinsip pengaturan ventilator pasien ARDS meliputi volume tidal rendah $(4-6 \mathrm{~mL} / \mathrm{kgBB}$ ) dan PEEP yang adekuat, kedua pengaturan ini dimaksudkan untuk memberikan oksigenasi adekuat $\left(\mathrm{PaO}_{2}>60 \mathrm{mmHg}\right)$ dengan tingkat $\mathrm{FiO}_{2}$ aman, menghindari barotrauma (tekanan saluran napas < $30 \mathrm{cmH}_{2} \mathrm{O}$ ) dan menyesuaikan (I:E) rasio inspirasi: ekspirasi. Hal tersebut ditujukan dengan maksud untuk memberikan oksigenasi yang adekuat, membuang karbondioksida dengan optimal, dan menghindari terjadinya komplikasi penggunaan ventilator berupa volutrauma dan barotrauma. ${ }^{12-15}$

Pada pasien ARDS, terjadi kolaps alveolus paru yang masif dan harus terjadi pembukaan alveolus pada setiap siklus napas yang kemudian akan mengakibatkan jejas alveolar. Menurut Amato dkk, ${ }^{4}$ strategi pengaturan ventilator protektif yang didesain khusus untuk pasien-pasien ARDS tidak hanya dapat menurunkan komplikasi tersebut, tetapi juga menurunkan mortalitas pada pasien ARDS. Pada strategi tersebut, dilakukan pembatasan dan pengurangan delta pressure dan volume tidal, dan menaikkan PEEP. ${ }^{16-17}$

Kelompok subyek dibagi menjadi dua kelompok berdasarkan penggunaan delta pressure, yaitu kelompok yang menggunakan delta pressure $\leq 13 \mathrm{cmH}_{2} \mathrm{O}$ dan $>13 \mathrm{cmH}_{2} \mathrm{O}$. Hal ini didasarkan pada penelitian yang dilakukan oleh Guerin $\mathrm{dkk}^{7}$ yang menyebutkan bahwa penggunaan pengaturan ventilator dengan delta pressure pada pasien anak dengan delta pressure $\leq 13 \mathrm{cmH}_{2} \mathrm{O}$ mempunyai risiko mortalitas yang lebih rendah dibandingkan dengan kelompok delta pressure $>13 \mathrm{cmH}_{2} \mathrm{O}$.

Perbandingan nilai mortalitas subyek berbeda antara delta pressure tinggi dan rendah. Didapatkan kelompok subyek yang menggunakan delta pressure tinggi memiliki risiko 45 kali lipat untuk terjadinya 
Tressa Bayu B dkk: Perbandingan mortalitas pasien ARDS yang menggunakan delta pressure tinggi dan rendah

mortalitas dibandingkan dengan kelompok subyek delta pressure rendah. Penelitian Amato ${ }^{4}$ mendapatkan hasil bahwa delta pressure adalah faktor risiko terpenting yang memengaruhi mortalitas pasien ARDS. Pada kelompok risiko dengan delta pressure tinggi, risiko mortalitas akan meningkat $45 \%$ bila dibandingkan dengan kelompok subyek dengan delta pressure rendah. ${ }^{7}$ Pada penelitian ini digunakan uji statistik chi square, hanya variabel delta pressure yang digunakan sebagai variabel independen dan mortalitas sebagai variabel dependen.

Pada penelitian Guerin $\mathrm{dkk}^{7}$ juga disebutkan bahwa dengan adanya peningkatan delta pressure sebesar $1 \mathrm{cmH}_{2} \mathrm{O}$ akan meningkatkan risiko mortalitas sebesar 5\%. Dengan demikian, dapat disimpulkan dari penelitian tersebut, bahwa semakin tinggi penggunaan delta pressure maka risiko mortalitas pada pasien akan semakin meningkat. Sejalan dengan hasil penelitian ini bahwa pada kelompok yang menggunakan delta pressure tinggi, jumlah mortalitasnya lebih tinggi dibandingkan dengan kelompok subyek dengan penggunaan delta pressure yang rendah.

Salah satu alasan yang mendasari hal tersebut adalah delta pressure memengaruhi besarnya volume tidal dan besarnya bagian paru yang teraerasi. Semakin tinggi delta pressure yang digunakan untuk menghasilkan bagian paru yang berfungsi untuk pertukaran oksigen maka pada kondisi tersebut komplians paru buruk. Komplians paru yang buruk meningkatkan risiko mortalitas karena semakin rendah komplians paru maka semakin tinggi pula derajat inflamasi yang terjadi di parenkim paru dan alveolus yang menandakan derajat penyakit yang diderita pasien juga semakin berat. Namun demikian, faktor delta pressure tidak dapat terlepas dari faktor lain yang berpengaruh terhadap luasnya bagian paru yang dapat berfungsi untuk pertukaran oksigen, seperti PEEP dan volume tidal. ${ }^{18-20}$

Pada penelitan yang dilakukan oleh Guerin $\mathrm{dkk}^{7}$ disebutkan bahwa faktor delta pressure bukanlah satu-satunya faktor independen dalam memprediksi mortalitas. Faktor besarnya PEEP dan volume tidal yang diberikan juga berkontribusi untuk terjadinya mortalitas. Stephen $\mathrm{dkk}^{20}$ juga menyebutkan bahwa faktor besarnya delta pressure sebagai prediktor paling kuat untuk mortalitas pasien dengan ARDS yang dikemukakan Amato dkk lebih dapat disebut sebagai hipotesis dibanding dengan temuan definitif. ${ }^{18-21}$

\section{Kesimpulan}

Terdapat perbedaan mortalitas antara pasien anak dengan ARDS pada penggunaan delta pressure yang tinggi dibandingkan dengan delta pressure yang rendah. Pada penggunaan delta pressure yang tinggi, maka risiko mortalitas juga akan semakin besar.

\section{Daftar pustaka}

1. Susan I, Sharath P, Malachy C, Jean-Louis V, Mahesh N. Does a higher positive end expiratory pressure decrease mortality in acute respiratory distress syndrome?. Anesthesiology 2009;5:1098-105.

2. Michael R, Anderson M. Update on pediatric acute respiratory distress syndrome. Respiratory Care 2003;48:1-73.

3. Alejandro D, Daniela A, Franco D, Pablo C. Ventilation strategies in the child with severe hypoxemic respiratory failure. Gac Med Mex 2015;151:69-77.

4. Amato M, Meade M, Slutsky A, Brochard L, Costa EL, Schoenfeld DA, dkk. Driving pressure and survival in the acute respiratory distress syndrome. N Engl J Med 2015;372:74755.

5. Desai AR, Deep A. Ventilatory Strategies and Adjunctive Therapy in ARDS. Indian J Pediatrics 2006;73:661-8.

6. Cheifetz I. Pediatric acute respiratory distress syndrome. Respir Care 2011;56:1589-99.

7. Guérin C, Papazian L, Reignier J, Ayzac L, Loundou A, Forel J. Effect of driving pressure on mortality in ARDS patients during lung protective mechanical ventilation in two randomized controlled trials. Crit Care 2016;20:1-9.

8. Brioni M, Cressoni M, Chiumello D, Carlesso E, Brioni M, Cressoni M. Airway driving pressure and lung stress in ARDS patients. Crit Care Med 2016;20:276 http://dx.doi. org/10.1186/s13054-016-1446-7.

9. Asbaugh D, Bigelow B, Thomas L, Bernard E, Levine. Acute respiratory distress in adults. The Lancet 1967;190:319-323.

10. Fanelli V, Vlachou A, Ghannadian S, Simonetti U, Slutsky AS, Zhang H. Acute respiratory distress syndrome : new definition, current and future therapeutic options. J Thorac Dis 2013;5:326-34.

11. The Pediatric Acute Lung Injury Consensus Conference Group. Pediatric acute respiratory distress syndrome: consensus recommendations from the pediatric acute lung injury consensus conference. Pediatr Crit Care Med 2015;1-12.

12. Serrate AS, Castelani P, Albano L, Podesta F, Farias JA. Characterization of pediatric patients receiving prolonged mechanical ventilation mechanical ventilation. Pediatr Crit 
Tressa Bayu B dkk: Perbandingan mortalitas pasien ARDS yang menggunakan delta pressure tinggi dan rendah

Care Med 2011;12:e287-91.

13. Carmen S, Barbas V, Amato P, dkk. Goal-oriented respiratory management for critically ill patients with acute respiratory distress syndrome. Crit Care Res Prac 2012;2012. Article ID 952168, 13 pages http://dx.doi.org/10.1155/2012/952168.

14. Rotta AT, Steinhorn DM. Conventional mechanical ventilation in pediatrics. J de Pediatria 2007;83:100-8.

15. Cheifetz I. Invasive and noninvasive pediatric mechanical ventilation. Respir Care 2003;48:442-58.

16. Amin Z, Purwoto J. Acute respiratory distress syndrome (ARDS). Dalam: Sudoyo AW, Setiyohadi B, Alwi I, penyunting. Buku Ajar Ilmu Penyakit Dalam. Balai Penerbit FKUI; 2009.h.4072-9.
17. Khemani RG, Morris A, Dean JM, Newth CJL. Variability in usual care mechanical ventilation for pediatric acute lung injury : the potential benefit of a lung protective computer protocol. Intensive Care Med 2011;37:1840-8.

18. Girard TD, Bernard GR. Mechanical ventilation in ARDS: A State-of-the-Art Review. Chest 2007;131:921-9.

19. Davide C, Eleonora C, Matteo B, Massimo C. Airway driving pressure and lung stress in ARDS patients. Biomed Central Crit Care 2016;20:276.

20. Stephen H, Loring, Atul M. Driving pressure and respiratory mechanics in ARDS. N Engl J Med 2015; 372:776-7.

21. João B, Göran H, Anders L, Fernando S. Altering the mechanical scenario to decrease the driving pressure. Biomed Central Crit Care 2015;19:342. 